\title{
Assessing the Development of Collective Impact Initiatives Addressing Maternal and Child Health
}

\author{
Sarah Landry ${ }^{1}\left[\right.$ Vicki Collie-Akers $^{1} \cdot$ Kara Foster $^{2} \cdot$ Denise Pecha $^{2} \cdot$ Chad Abresch $^{2}$
}

Published online: 12 February 2020

(c) The Author(s) 2020

\begin{abstract}
Purpose To examine the extent to which communities participating in the Collective Impact Learning Collaborative (CILC) increased capacity to create conditions for collective impact (CI) to address racial disparities in maternal and child health $(\mathrm{MCH})$ and align local efforts with state $\mathrm{MCH}$ priorities over a 12-month period.

Description Eight communities participated in a learning collaborative that involved the provision of technical assistance via webinars, monthly team calls, and site visits to facilitate the development of a collective impact initiative. A Ready-Set-Go approach to technical assistance was used to guide the communities through each phase of development while also providing individual assistance to teams based on their capacity at the start of participation.

Assessment A pre/post design measured change in capacity to engage in CI efforts over time. A survey designed to assess the completion of core tasks related to early indicators of CI was completed at baseline and 12 months later. Wilcoxon Signed Ranks Test and Mann-Whitney test determined statistically significant progress towards outcomes over 12 months and differences in progress between high- and low- capacity teams.

Conclusion In 12 months, teams with little established groundwork made significant progress, in some ways exceeding progress of more established teams. Statistically significant progress was achieved in eleven of fourteen outcomes measured. Five teams aligned local efforts with state priorities after 12 months. Findings suggest technical assistance to establish conditions for collective impact can support progress even when pre-conditions for collective impact are not previously established.
\end{abstract}

Keywords Collective impact · Maternal and child health $\cdot$ Evaluation $\cdot$ Technical assistance

Sarah Landry

slandry@kumc.edu

Vicki Collie-Akers

vcollieakers@kumc.edu

Kara Foster

kara.foster@unmc.edu

Denise Pecha

denise.pecha@unmc.edu

Chad Abresch

cabresch@unmc.edu

1 Department of Population Health, University of Kansas School of Medicine, 3901 Rainbow Boulevard, Kansas City, KS 66160, USA

2 University of Nebraska Medical Center, 982170 Nebraska Medical Center, Omaha, NE 68198-2170, USA

\section{Significance}

The life course perspective is often applied in practice and research related to racial and health disparities in $\mathrm{MCH}$. This calls for novel approaches to collaboration in order to more fully integrate systems along the continuum of care that intervenes at various life stages.

Examination of the implementation of the first phases of a collective impact model suggest that a significant amount of progress can be made in a relatively short amount of time to establish the groundwork for collaboration and implementation of strategies to address racial disparities in maternal and child health and align local and state priorities regardless of capacity to begin the work. 


\section{Purpose}

Life course theory provides a framework to view stages of development (e.g. infancy, adolescence, adulthood) as an integrated whole where intervention to improve protective factors for health should occur at each phase to increase odds of better health outcomes at later phases (Fine et al. 2009). This approach requires public health organizations play a role in improving maternal and child health $(\mathrm{MCH})$ clinical outcomes, but also early education, housing, community networks, and the private sector as they relate to influencing the quality of a school, safety of a home, connectedness to neighbors, and opportunity for employment across the span of one's life. To improve MCH across the life course, diverse multi-sector collaboration is required (Lu 2014). Models of collaboration describe processes and principles that coalitions adopt when convening stakeholders to address complex issues (e.g. Butterfoss and Kegler 2009; Fawcett et al. 2010; Wolff 2010; Kania and Kramer 2011). However, a challenge posed by life course theory, is to move beyond collaboration to "multi-dimensional systems integration" (Lu 2014, p. 341). This approach means moving from a focus on impact of some organizations to developing capacity for collective impact across levels of intervention (e.g. individual, community), systems and sectors, and longitudinally across the continuum of care that intervenes at various life stages (Lu 2014).

The collective impact (CI) model is a useful framework for systems integration to address $\mathrm{MCH}$ issues from a life course perspective. Core components of the CI model include principles of collaboration, coalition development, and community organizing described in literature (e.g. Butterfoss and Kegler 2009; Fawcett et al. 2010; Wolff 2010). However, a focus of the CI model is aligning goals and activities across systems and sectors with support from a system of governance that promotes strategic planning, community involvement, and continuous evaluation (Preskill et al. 2014; Hanleybrown et al. 2012).

This paper explores the extent to which communities created conditions for $\mathrm{CI}$ to address $\mathrm{MCH}$ outcomes through technical assistance (TA) as a participant in the Collective Impact Learning Collaborative (CILC). The Collaborative was funded through the Health Resources and Services Administration's (HRSA) Maternal and Child Health Bureau to create greater alignment between state and local $\mathrm{MCH}$ priorities. Federal funding for $\mathrm{MCH}$ is provided through Title V of the Social Security Act. Title V is a federal-state partnership providing funding and support to address complex problems like access to quality health care and reduction of infant mortality. The flexibility of the block grant allows state health departments (HD) to prioritize and fund the greatest needs.
While Title $\mathrm{V}$ is a federal-state partnership, many important elements of $\mathrm{MCH}$ programming are planned and implemented by local HDs. Local HDs may align priorities and activities to enhance progress toward the $\mathrm{MCH}$ needs identified by states. Thus, the CI model was used to focus on systems integration and alignment to support effective use of resources to address MCH outcomes. Establishing more evidence regarding the extent to which $\mathrm{CI}$ is a useful model for state and local alignment and what role technical assistance and community capacity might play in that process can inform best practice for community based $\mathrm{MCH}$ initiatives.

The CI model describes three pre-conditions and five phases of implementation. Pre-conditions include the presence of an influential champion, adequate financial resources, and a sense of urgency for change among community and partners (Hanleybrown et al. 2012). Five phases of CI include assessing readiness, initiating action, organizing for impact, beginning implementation, and sustaining action and impact (Preskill et al. 2014). During each phase, communities develop five conditions for CI: forming a common agenda, developing a shared measurement system, establishing mutually reinforcing activities, continuous communication, and creating a backbone infrastructure (Preskill et al. 2014).

\section{Description}

CityMatCH, the National Organization of $\mathrm{MCH}$ leaders, entered a cooperative agreement with HRSA to provide technical assistance to local HDs to address Title V MCH priorities in their communities. HDs completed a questionnaire to assess readiness to begin a $\mathrm{CI}$ initiative. Seventy-one HDs completed the questionnaire. Thirty local HDs expressed interest in participation in the collaborative and had not received any previous training or TA support for CI. These HDs were invited to participate in one of the three cohorts beginning in 2016 through 2018. Each cohort consisted of representatives from ten local HDs and their community partners.

HDs were asked to assemble community representatives and HD staff to act as a core team responsible for mobilizing and organizing partners to address $\mathrm{MCH}$ priorities. Core teams varied in readiness to participate. Higher capacity teams met some pre-conditions for $\mathrm{CI}$ including having dedicated resources for a CI initiative, previously formed coalition, and knowledge about core principles of CI. Lower capacity teams had no financial resources or experience with the CI model, but in some cases had champions able to bring organizations together. Cohorts were arranged so both high- and low-capacity teams were included in each cohort to support peer mentorship. Analysis and results that follow include data from the first cohort of teams. 
CityMatCH provided TA via webinars, monthly calls, and site visits based on a Ready-Set-Go framework (CityMatCH 2018). The Ready phase supported teams in building leadership, community and stakeholder buy-in, and gathering and analyzing information about priority $\mathrm{MCH}$ issues. Webinars with expert practitioners and monthly TA calls covered topics like connecting teams with their Title V Directors, core principles and strategies for CI, engaging community members and champions, and building a coalition with stakeholders from multiple sectors. The Set phase focused on narrowing down the work, prioritizing equity in CI work, and creating agendas for coalition meetings (e.g. tools, logistics, language and messaging). TA during the Go phase centered around evaluation and developing conditions for sustainability. However, this phase of TA was not implemented during the survey period reported. By providing TA, it was expected teams could engage in processes for spurring collaborative action and establish early conditions for $\mathrm{CI}$ that would address MCH priorities (Fig. 1).

\section{Assessment}

A pre/post evaluation design measured change in team capacity to engage in CI efforts over time. A survey developed from the Best Change Processes framework was used (Roussos and Fawcett 2000). Completion of core tasks related to Best Change Processes increase a group's ability to affect change, are associated with more robust community-level interventions (Keene-Woods 2014; WatsonThompson 2015; Fawcett et al. 2010), and align with early outcomes for CI identified by Preskill et al. (2014).

Core tasks were indicators of progress as they related to specific outcomes proposed by Preskill et al. (2014) in their Guide to Evaluating Collective Impact. The number

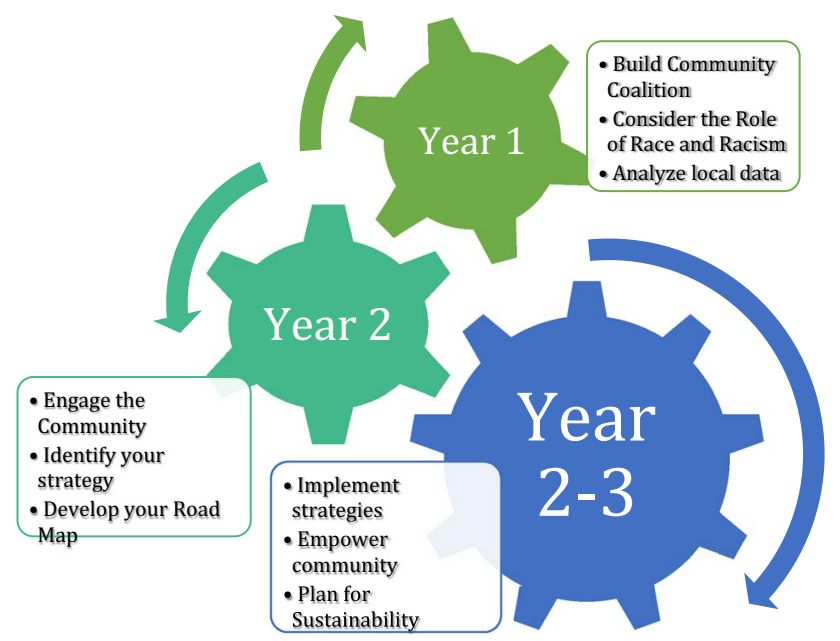

Fig. 1 Ready-set-go framework of completed tasks measured the extent to which communities produced early outcomes of success. Team leaders completed the survey prior to participation in the CILC and 12 months later. The survey consisted of 92 questions with "Yes", "No", or "Don't Know" response options depending on completion of core tasks. One survey was completed per team. Respondents were asked to choose "Yes" if the task was fully completed, "No" if only partially completed, or "Don't Know" if they were unsure. Evaluation protocols were submitted to University of Kansas IRB for approval and were deemed exempt from review.

Table 1 provides a list of early outcomes and examples of selected indicators.

The percent of tasks completed were calculated at baseline and 12 months. The number of "Yes" responses affirming completion of tasks were summed for each early outcome. The sum was then divided by the total number of possible tasks for each outcome measure to establish a percent complete in each community. The percent of completed tasks was averaged across communities to assess progress overall. This analysis was completed for high capacity and low capacity teams to compare progress between groups. The non-parametric Wilcoxon Signed Ranks Test determined if there were statistically significant differences within teams over time. The non-parametric Mann-Whitney test determined statistically significant differences between high- and low- capacity teams at baseline and 12 months. Two teams withdrew participation after several months due to staff turnover. Results include the eight remaining teams.

\section{Conclusion}

Statistically significant progress was determined in eleven of fifteen outcomes (Table 2).

Teams made most progress ensuring inclusion of diverse sectors in developing leadership and a common agenda. Core tasks included establishing leadership inclusive of diverse skill sets, experience, interest/expertise, and ensuring community stakeholders had an opportunity to analyze information about the issue and assess its importance. Two teams indicated development of a common agenda at baseline. Neither of the teams with common agendas at baseline demonstrated state alignment. Alternatively, five teams that developed common agendas during the first 12 months of the CILC were aligned with state priorities. Teams made considerable progress towards establishing processes to engage external stakeholders by providing opportunities to propose strategies and solutions and regularly communicate progress towards developing and completing an action plan. Progress made in these areas is not surprising as they are natural places to begin collaborative work and are required to establish 
Table 1 Phase 1 and 2 outcomes for success in collective impact

\begin{tabular}{|c|c|c|}
\hline Core component of CI & Early outcomes & Example select indicators \\
\hline \multirow[t]{4}{*}{ Common agenda } & $\begin{array}{l}\text { Common agenda was developed that included a } \\
\text { diverse set of voices and multiple sectors }\end{array}$ & $\begin{array}{l}\text { Populations affected by the problem were identified and } \\
\text { engaged in assessing its importance }\end{array}$ \\
\hline & $\begin{array}{l}\text { Partners achieved a common understanding of the } \\
\text { problem }\end{array}$ & $\begin{array}{l}\text { The group identified the type(s) of problems or goals } \\
\text { that it will address to help focus its efforts }\end{array}$ \\
\hline & $\begin{array}{l}\text { Partners have consensus on the initiative's ultimate } \\
\text { goal and shared vision for change }\end{array}$ & $\begin{array}{l}\text { The group has engaged stakeholders in the develop of a } \\
\text { mission statement }\end{array}$ \\
\hline & $\begin{array}{l}\text { Partners are committed to using an adaptive approach } \\
\text { with agreed upon strategies and actions }\end{array}$ & $\begin{array}{l}\text { The group has written strategies that are approved by } \\
\text { the group and state how goals will be accomplished }\end{array}$ \\
\hline \multirow[t]{3}{*}{ Backbone infrastructure } & $\begin{array}{l}\text { Backbone infrastructure effectively guides the CI } \\
\text { initiative's vision and strategy }\end{array}$ & Leaders guide important processes and act as facilitators \\
\hline & $\begin{array}{l}\text { Backbone infrastructure ensures alignment of existing } \\
\text { activities and pursuit of new opportunities toward } \\
\text { the initiative's goal }\end{array}$ & $\begin{array}{l}\text { The group reviews the strategic/action plan and makes } \\
\text { necessary modifications and updates }\end{array}$ \\
\hline & $\begin{array}{l}\text { Backbone infrastructure supports the collection and } \\
\text { use of data to promote accountability, learning, and } \\
\text { improvement }\end{array}$ & $\begin{array}{l}\text { The group regularly reviews the date about the imple- } \\
\text { mentation of the intervention or initiative }\end{array}$ \\
\hline \multirow[t]{3}{*}{ Mutually reinforcing activities } & Partners developed and use a collective plan of action & $\begin{array}{l}\text { Action plans indicate what will be done, by whom and } \\
\text { by when }\end{array}$ \\
\hline & $\begin{array}{l}\text { Partners coordinate activities to align with plan of } \\
\text { action }\end{array}$ & $\begin{array}{l}\text { The group has written objectives to guide the efforts of } \\
\text { the initiative }\end{array}$ \\
\hline & $\begin{array}{l}\text { Partners have (re)allocated resources in support of the } \\
\text { collective impact initiative }\end{array}$ & $\begin{array}{l}\text { The group prioritized the choice of strategies based } \\
\text { on the importance of meeting obj. and feasibility of } \\
\text { strategies }\end{array}$ \\
\hline \multirow[t]{3}{*}{ Shared measurement } & $\begin{array}{l}\text { Partners understand the value of the shared measure- } \\
\text { ment system }\end{array}$ & $\begin{array}{l}\text { The group identified the types of data and information } \\
\text { important to stakeholders and other audiences }\end{array}$ \\
\hline & $\begin{array}{l}\text { The process of designing and managing the shared } \\
\text { measurement system is participatory and transparent }\end{array}$ & $\begin{array}{l}\text { The group developed a set of evaluation questions that } \\
\text { are important to stakeholders and key audience }\end{array}$ \\
\hline & $\begin{array}{l}\text { The shared measurement system has been designed to } \\
\text { track progress toward CI outcomes }\end{array}$ & $\begin{array}{l}\text { The group documents the activities used to address the } \\
\text { problem/goal }\end{array}$ \\
\hline \multirow[t]{2}{*}{ Continuous communication } & $\begin{array}{l}\text { Structures and processes are in place to engage part- } \\
\text { ners, keeping them informed and inspired }\end{array}$ & $\begin{array}{l}\text { The organization appropriately documents and record } \\
\text { organizational activities (e.g. meeting minutes) }\end{array}$ \\
\hline & $\begin{array}{l}\text { Structures and processes are in place to engage the } \\
\text { initiative's external stakeholders, keeping them } \\
\text { informed and inspired }\end{array}$ & $\begin{array}{l}\text { The group regularly communicates progress toward } \\
\text { completing the strategic/action plan to the staff, board, } \\
\text { and other key stakeholders }\end{array}$ \\
\hline
\end{tabular}

support and a common understanding of the problem and solution. Less progress was made toward establishing a backbone infrastructure, mutually reinforcing activities, and a shared measurement system. These conditions are more challenging to address and are often dependent upon successes related to developing a common agenda, leadership, and building trust among stakeholders. For example, progress toward developing mutually reinforcing activities and shared measurement may be hindered if groups are unable to fully form a common agenda. Similarly, identifying leadership and building trust within the community and among new partners is required to make progress establishing a backbone infrastructure where one doesn't previously exist.

Statistically significant differences were not identified at baseline or 12 months between high- and low-capacity teams. However, teams with lower levels of capacity often exceeded the progress of high capacity teams. Figures 2 and
3 display the average percent of tasks completed at baseline and 12 months by low $(n=5)$ and high $(n=3)$ capacity teams.

\section{Common Agenda}

Prior to participating, low- and high-capacity teams took similar steps to lay the groundwork to develop a common agenda. For example, all teams had identified the types of problems or goals they hoped to address. Similarly, all but one team had identified where or among whom their efforts should be focused. However, teams with higher capacity had analyzed data, identified risk and protective factors, established vision and mission statements, and identified potential strategies for addressing issues prior to participation.

Teams with lower capacity made substantial progress collecting and reviewing data about the issues and getting 
Table 2 Early outcomes of success for collective impact and community and system change

\begin{tabular}{|c|c|c|c|}
\hline \multirow{2}{*}{$\begin{array}{l}\text { Early outcomes } \\
\text { Common agenda }\end{array}$} & \multirow{2}{*}{$\begin{array}{l}\text { Baseline } \\
\text { Average percent of completed tasks } \\
\text { for achieving benchmarks (Mdn, } \\
\text { IQR) }\end{array}$} & \multicolumn{2}{|l|}{12 Months } \\
\hline & & $\begin{array}{l}\text { Average percent of completed tasks } \\
\text { for achieving benchmarks (Mdn, } \\
\text { IQR) }\end{array}$ & $\begin{array}{l}\text { Wilcoxon signed-rank } \\
\text { test } Z \text { score (p-value) }\end{array}$ \\
\hline $\begin{array}{l}\text { Common agenda was developed that } \\
\text { included a diverse set of voices and } \\
\text { multiple sectors }\end{array}$ & $28 \%(37.5,50)$ & $69 \%(75,18.75)$ & $-2.232(.026)^{*}$ \\
\hline $\begin{array}{l}\text { Partners achieved a common understand- } \\
\text { ing of the problem }\end{array}$ & $60 \%(50,73)$ & $87 \%(87.5,25)$ & $-2.032(.042)^{*}$ \\
\hline $\begin{array}{l}\text { Partners have consensus on the initia- } \\
\text { tive's ultimate goal and shared vision for } \\
\text { change }\end{array}$ & $15 \%(7,5.5)$ & $56 \%(71,50.75)$ & $-2.371(.018)^{*}$ \\
\hline $\begin{array}{l}\text { Partners are committed to using an adap- } \\
\text { tive approach with agreed upon strate- } \\
\text { gies and actions }\end{array}$ & $39 \%(36,61.5)$ & $67 \%(68,28.5)$ & $-2.207(.027)^{*}$ \\
\hline \multicolumn{4}{|l|}{ Backbone infrastructure } \\
\hline $\begin{array}{l}\text { Backbone infrastructure effectively } \\
\text { guides the CI initiative's vision and } \\
\text { strategy }\end{array}$ & $19 \%(6.5,34)$ & $53 \%(56.5,46.75)$ & $-1.970(.049)^{*}$ \\
\hline $\begin{array}{l}\text { Backbone infrastructure ensures align- } \\
\text { ment of existing activities and pursuit } \\
\text { of new opportunities toward the initia- } \\
\text { tive's goal }\end{array}$ & $29 \%(0,67)$ & $58 \%(66.5,34)$ & $-1.372(.170)$ \\
\hline $\begin{array}{l}\text { Backbone infrastructure supports the } \\
\text { collection and use of data to promote } \\
\text { accountability, learning, and improve- } \\
\text { ment }\end{array}$ & $12 \%(0,9.75)$ & $24 \%(19,34.75)$ & $-1.581(.114)$ \\
\hline \multicolumn{4}{|l|}{ Mutually reinforcing activities } \\
\hline $\begin{array}{l}\text { Partners developed and use a collective } \\
\text { plan of action }\end{array}$ & $19 \%(0,37.5)$ & $25 \%(0,75)$ & $-1.000(.317)$ \\
\hline $\begin{array}{l}\text { Partners coordinate activities to align with } \\
\text { plan of action }\end{array}$ & $19 \%(8.5,33)$ & $63 \%(67,41.5)$ & $-2.375(.018)^{*}$ \\
\hline $\begin{array}{l}\text { Partners has (re)allocated resources in } \\
\text { support of the collective impact initia- } \\
\text { tive }\end{array}$ & $8 \%(0,0)$ & $33 \%(16.5,83.3)$ & $-1.890(.059)$ \\
\hline \multicolumn{4}{|l|}{ Shared measurement } \\
\hline $\begin{array}{l}\text { Partners understand the value of the } \\
\text { shared measurement system }\end{array}$ & $17 \%(16.5,33)$ & $54 \%(67,34)$ & $-2.226(.026)^{*}$ \\
\hline $\begin{array}{l}\text { The process of designing and manag- } \\
\text { ing the shared measurement system is } \\
\text { participatory and transparent }\end{array}$ & $6 \%(0,0)$ & $38 \%(50,37.5)$ & $-2.236(.025)^{*}$ \\
\hline $\begin{array}{l}\text { The shared measurement system has } \\
\text { been designed to track progress toward } \\
\text { the CI's outcomes }\end{array}$ & $14 \%(0,18.75)$ & $41 \%(37.5,68.75)$ & $-2.020(.043)^{*}$ \\
\hline \multicolumn{4}{|l|}{ Continuous communication } \\
\hline $\begin{array}{l}\text { Structures and processes are in place } \\
\text { to engage partners, keeping them } \\
\text { informed and inspired }\end{array}$ & $25 \%(0,55)$ & $73 \%(70,35)$ & $-2.036(.042)^{*}$ \\
\hline $\begin{array}{l}\text { Structures and processes are in place } \\
\text { to engage the initiative's external } \\
\text { stakeholders, keeping them informed } \\
\text { and inspired }\end{array}$ & $16 \%(0,37.5)$ & $69 \%(75,50)$ & $-2.414(.016)^{*}$ \\
\hline
\end{tabular}

$* p<.05$ 


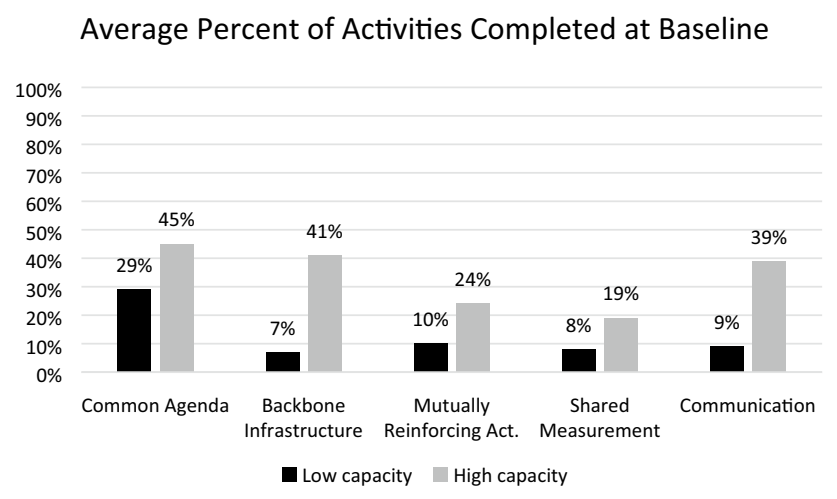

Fig. 2 Average percent of activities completed at baseline

Average Percent of Activities Completed at 12 Months

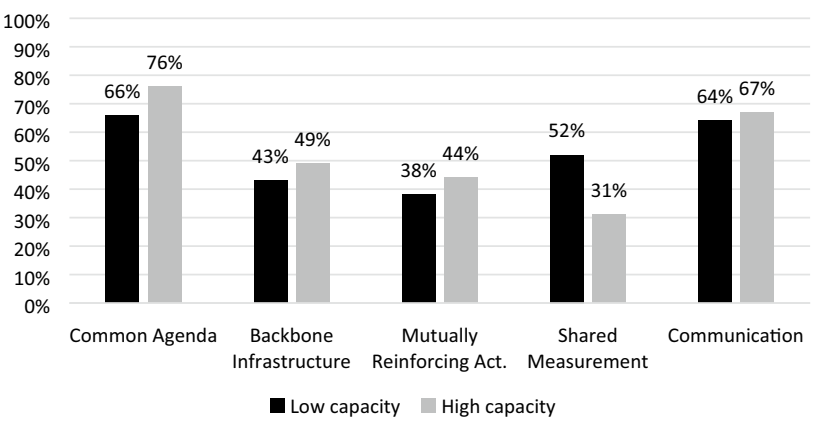

Fig. 3 Average percent of activities completed at 12 months

input from community. These teams identified behavioral and environmental factors related to their priorities, established vision and mission statements, and reviewed evidence-based strategies to address the issue. Higher capacity teams completed these steps prior to baseline and could focus attention on aligning goals and strategies among stakeholders.

\section{Backbone Infrastructure}

High capacity teams had taken several steps toward establishing a backbone infrastructure at baseline. Teams had a clear governing structure, method for operating (e.g. committees, staffing), and leadership able to connect the group to appropriate resources. None of the lower capacity teams reported these accomplishments at baseline. However, within 12 months, three lower capacity teams reported reaching those milestones. Considering few teams entered the CILC with backbone organizations established, it is to be expected that most of the focus during this period was on developing the infrastructure itself.

\section{Mutually Reinforcing Activities}

The amount of action taken to establish mutually reinforcing activities were similar at baseline and at 12 months, regardless of team capacity. After 12 months, one high and one low capacity team, completed an action plan and prioritized strategies to implement. By 12 months, all lower capacity teams brought stakeholders together to develop a strategic plan including components like a clear mission and objectives.

\section{Shared Measurement}

Although one high capacity team established a shared measurement system prior to participation, all other teams had little established at baseline. After 12 months, all teams in the low capacity group identified the type of data important to stakeholders. Similarly, four low capacity teams identified data sources and assured access to measures. Regardless of capacity, four of the eight teams made considerable progress towards designing a system to track outcomes, especially to document activities and collect longer-term measures. Unlike other components of CI, lower capacity teams made more progress in this area.

\section{Communication}

Low capacity teams outperformed high capacity teams in establishing structures and processes for continuous communication. Two of the three high capacity teams had established processes prior to the start of the CILC leaving less room for progress. However, all low capacity teams began participation with either new or yet-to-be developed groups of stakeholders. These teams viewed the establishment of roles and responsibilities, meeting schedules, and development of other methods for communication as priority for developing a common agenda and mutually re-enforcing activities.

\section{Discussion}

Overall most progress was made toward developing a common agenda and establishing communication mechanisms among partners. Taking action in these areas are the easiest and most logical first steps towards creating conditions for collective impact. Future assessment may permit the establishment of patterns of activity over time.

Teams made similar progress regardless of level of capacity at baseline indicating that pre-conditions are important 
but should not preclude teams from engaging in CI. Teams with little established groundwork made an exceptional amount of progress and, in some ways, exceeded progress made by more established teams. These findings may have a few explanations. Lower capacity teams developed new partnerships to support the work which appeared more open to fully adopting a CI framework. Core teams reported that TA provided the accountability needed to bring new partners along and accelerate progress during the initial phases of the work. High capacity teams worked within long-standing coalitions which offered benefits and challenges. Coalitions were large in number and able to generate resources and support at high levels (e.g. State HDs). However, core teams often found it harder to garner support of decision-makers to move away from the status quo and towards a new way of operating, particularly when establishing shared measurement systems. Established infrastructure and support for CI can be advantageous to bring communities closer to acting on $\mathrm{MCH}$ priorities within 12 months. However, it may come with challenges that slow progress by requiring core team members to put more effort on garnering support for new approaches to the shared work.

Core teams may have made progress in these areas without the direct involvement of TA support. However, a common refrain among all core teams was that TA provided knowledge, encouragement, and accountability which furthered progress beyond what they may have achieved on their own. TA providers helped teams reflect on progress by asking hard questions to move out of comfort zones, focus on core principles of $\mathrm{CI}$, and provide benchmarks and timelines for progress. Communities interested in organizing to align activities and resources to address $\mathrm{MCH}$ outcomes can benefit from technical assistance that combines expert sources of information, encouragement, and accountability coupled with a clear CI framework for action regardless of pre-existing infrastructures or resources to begin the work.

Funding This funding was supported by Maternal and Child Health Bureau.

Open Access This article is licensed under a Creative Commons Attribution 4.0 International License, which permits use, sharing, adaptation, distribution and reproduction in any medium or format, as long as you give appropriate credit to the original author(s) and the source, provide a link to the Creative Commons licence, and indicate if changes were made. The images or other third party material in this article are included in the article's Creative Commons licence, unless indicated otherwise in a credit line to the material. If material is not included in the article's Creative Commons licence and your intended use is not permitted by statutory regulation or exceeds the permitted use, you will need to obtain permission directly from the copyright holder. To view a copy of this licence, visit http://creativecommons.org/licenses/by/4.0/.

\section{References}

Butterfoss, F., \& Kegler, M. (2009). The community coalition action theory. In R. DiClemente, R. Crosby, \& M. Kegler (Eds.), Emerging theories in health promotion practice and research (2nd ed., pp. 238-274). San Francisco, CA: Jossey-Bass.

CityMatCH. (2018). Institute for Equity in Birth Outcomes: eLearning Community. Retrieved February 6, 2020, from https://www.citym atchlearning.org/equity/.

Fawcett, S., Schultz, J., Watson-Thompson, J., Fox, M., \& Bremby, R. (2010). Building multi sectoral partnerships for population health and health equity. Preventing Chronic Disease, 7(6), 1-7.

Fine, A., Kotelchuck, M., Adess, N., Pies, C. (2009). Policy brief. A new agenda for $\mathrm{MCH}$ Policy and Programs: Integrating a life course perspective. Martinez, CA: Contra Costa Health Services.

Hanleybrown, F., Kania, J., Kramer, M. (2012). Channeling change: Making collective impact work. Stanford Social Innovation Review. Retrieved February 6, 2020, from https://ssir.org/artic les/entry/channeling_change_making_collective_impact_work.

Kania, J., \& Kramer, M. (2011). Collective impact. Stanford Social Innovation Review. Retrieved February 6, 2020, from https://ssir. org/articles/entry/collective_impact.

Keene-Woods, N., Watson-Thompson, J., Schober, D., Markt, B., \& Fawcett, S. (2014). An empirical case study of the effects of training and technical assistance on community coalition functioning and sustainability. Health Promotion Practice, 15(5), 739-749.

Lu, M. (2014). Improving maternal and child health across the life course: Where do we go from here? Maternal Child Health Journal, 18, 339-343.

Preskill, H., Parkhurst, M., Juster, J. (2014). Guide to evaluating collective impact. Supplement: Sample questions, outcomes, and indicators. Retrieved February 6, 2020, from https://www.fsg.org/tools -and-resources/guide-evaluating-collective-impact-supplement.

Roussos, S., \& Fawcett, S. (2000). A review of collaborative partnerships as a strategy for improving community health. Annual Review of Public Health, 21, 369-402.

Watson-Thompson, J. (2015). Exploring community-engaged scholarship as an intervention to change and improve communities. Metropolitan Universities, 26, 11-34. Retrieved from https://files .eric.ed.gov/fulltext/EJ1092912.pdf.

Wolff, T. (2010). The power of collaborative solutions: Six principles and effective tools for building healthy communities. San Francisco, CA: Jossey-Bass.

Publisher's Note Springer Nature remains neutral with regard to jurisdictional claims in published maps and institutional affiliations. 